\title{
Microcomputer-based Interactive Distribution Planning
}

\author{
Madsen, Oli B.G.
}

Published in:

IEEE International Conference on Systems, Man, and Cybernetics, Proceedings

Publication date:

1988

Document Version

Publisher's PDF, also known as Version of record

Link back to DTU Orbit

Citation (APA):

Madsen, O. B. G. (1988). Microcomputer-based Interactive Distribution Planning. In IEEE International Conference on Systems, Man, and Cybernetics, Proceedings (Vol. Volume 1, pp. 341-344). IEEE.

\section{General rights}

Copyright and moral rights for the publications made accessible in the public portal are retained by the authors and/or other copyright owners and it is a condition of accessing publications that users recognise and abide by the legal requirements associated with these rights.

- Users may download and print one copy of any publication from the public portal for the purpose of private study or research.

- You may not further distribute the material or use it for any profit-making activity or commercial gain

- You may freely distribute the URL identifying the publication in the public portal

If you believe that this document breaches copyright please contact us providing details, and we will remove access to the work immediately and investigate your claim. 


\author{
MICROCOMPUTER-BASED \\ INTERACTIVE DISTRIBUTION PLANNING \\ Oli B.G. Madsen \\ IMSOR \\ THE INSTITUTE OF MATHEMATICAL STATISTICS \\ AND OPERATIONS RESEARCH. \\ The Technical University of Denmark \\ DK-2800 Lyngby - Denmark
}

The effective and efficient management of goods and service has become increasingly. important in both the private and public sector. The importance of this is emphasized by the costs associated and the income effect. Of the total physical distribution management costs, the costs associated with routing and scheduling of vehicles constitute a very important part. Fuel costs, driver salaries and capital costs for vehicle maintenance are increasing dramatically. It is therefore of great importance for companies to reduce their fleet operation costs. We observe that due to the large costs, even small percentual improvements may be significant. Due to the complexity of the distribution problems including routing components, the use of operations research-based methods and algorithms is needed. Even for small problem sizes, the computer-based methods offer advantages over the manual methods not only with respect to cost reduction or profit improvement, but also in terms of, e.g., better customer service. The paper discusses the construction of a decision support system assisting the planner in charge of routing and scheduling tasks at the operational level. The system is implemented on an IBM PC and schould, therefore, be an economically feasible solution for companies of any size. The system will assist in solving both routing problems with one depot, and one depot routing and.scheduling problems where time constraints are imposed. The system is interactive, which makes it possible to incorporate usually unquantifiable factors on top of the solution process and to produce better solu- tions. The method is fast and may handle problems with several hundred customers.

$$
\text { i. Introduction }
$$

In a recent paper by Bocxe and Tilanus [1] concerning standard software for vehicle scheduling the conclusion was that there is a need for flexible, userfriendly, interactive, and cheap vehicle scheduling software. Papers by Belardo, Duchessi and Seagle [2], Bodin and Golden [3], Golden and Goodwin [4], and Golden and Wasil [5] support this conclusion. Furthermore the authors [2-5] recommend the use of microcomputers to meet the requirements of flexibility, user-friendliness, interactivity and cheapness.

The reasons for interactivity are among other things:

$$
\begin{aligned}
& \text { - not all factors in a problem can } \\
& \text { or are wanted to be quantified } \\
& \text { - an interactive system provides } \\
& \text { the user with more flexibility } \\
& \text { - it is possible to combine the } \\
& \text { speed of a computer, good soft- } \\
& \text { ware, and the experience of a } \\
& \text { distribution planner } \\
& \text { - experience shows that good plan- } \\
& \text { ners in fact are able to improve } \\
& \text { heuristic solutions considerably } \\
& \text { The reasons for implementation on a }
\end{aligned}
$$
personal computer are:

- personal computers are cheap

- it is rather easy to develop fast 
interactive graphics on a personal computer

Bodin and Golden [3] report or 13 American vehicle routing systems commercially available on a microcomputer. Two of the systems solve only the travelling salesman problem. The remaining 11 systems are grouped into two classes. The inexpensive vehicle routing packages ( 5 systems) generally costing less than US\$5000 and the more expensive routing packages ( 6 systems) costing between US\$ 10000 and 145000 (on the average around US $\$ 40000$ ).

Among the 11 systems all but one system require only an IBM XT/AT compatible personal computer with 256 or 512 kbytes. However only 5 of the 11 systems offer some graphics capabilities which is one of the key advantages of microcomputers. Only 3 of the 5 graphic systems are interactive. 2 of these systems are rather special purpose systems leaving only one system. The 3 interactive systems cost between US\$ 10000 and 145000 (on the average US\$51000).

Although the report mentioned above is written in 1985, and although the number of systems will increase and the cost of the systems will decrease there is still a need for more interactive graphics supported microcomputer-based systems for vehicle scheduling. This paper describes such a system developed at IMSOR by Bo Sørensen under supervision by the author in the period september 1983 to January 1987. The system which is named NIGA - Modular Interactive Graphics Approach - is implemented in Pascal on a personal computer.

Jörnsten, Madsen and Sørensen [6], and Kolen, Rinnooy Kan and Trienekens [7] have suggested optimum-finding methods for vehicle routing problems with time windows, while Solomon [8] has suggested several heuristic methods. Given the difficulty of this problem class, heuristic methods seem to offer the most promise for practical size problems.
The Interactive system

The MIGA system solves by heuristic methods vehicle scheduling problems with one depot, one commodity, a number of trucks with given capacities, a number of customers with given location, demand, service time, and time windows for delivery. The objective is to minimize:

- priority 1: the number of vehicles

- priority 2: the total scheduling time

- priority 3: the total distance travelled

The user may change the solution by an interactive dialog with the system. The user communicates with the system by the keyboard and mainly by a mouse. The keyboard is used for nondiscrete alpha-numeric information. The communication strategy is dialog based.

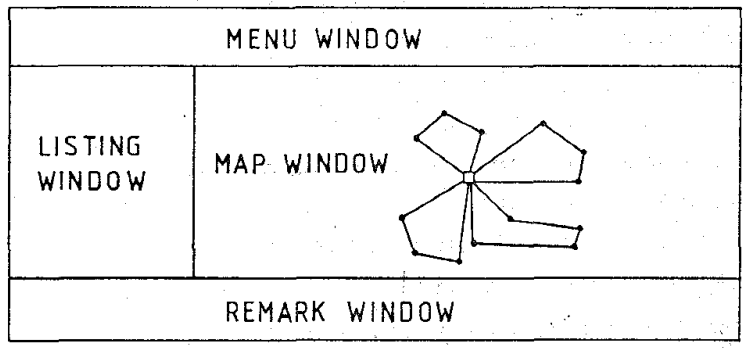

Figure 1 Screen layout

The screen layout is shown in figure 1. The main menu will always be present in the main menu window. This will give the user an opportunity to select an option from the main menu at any time, even when running a sub-menu; if so the sub-menu will be terminated, and the new option in the main menu. will be activated.

When selecting an option from the main menu, move the mouse cursor (an $x$ on the screen) to the appropriate option and press the button on the mouse, thereby "pulling down" the selected sub-menu. Still with the button pressed, the user points at the appropriate alternative and releases the button. The pull-down menu will disappear again and the selected action will be executed by the system. Figure 2 shows one of the pull-down menus - the SOLVE menu. Using this approach, the main menu is always present and the submenus will only appear when called for. 
Figure 2 Example of a pull-down menu (the SOLVE menu)

The listing window is used for displaying alpha-numeric listings of e.g. routes and schedules. The listing window is separated from the map window, allowing the user to work simultaneously with alpha-numeric and graphic illustrations of the problem.

The map window is primarily used to show the geographic area and the routes associated with the problem currently worked on.

The remark window contains two kinds of information. The far right end of the remark window will show the name associated with the current problem or geographic area. The left part of the window will display different help-information for the user, guiding the user smoothly through the problem-solving process.

In case an input of non-discrete alpha-numeric data is necessary all questions have been standardized to one form thereby avoiding to confront the user with a new kind of question each time an alpha-numeric input is needed.

In case of discrete choices between alternatives these are incorporated in the menus. Yes/no questions are answered by using the mouse.

When we are considering alpha-numeric display of data, colours serve the purpose of enhancing readability. The colours also serve the purpose of connecting alphanumeric information with the routes drawn on the map window. This is done by using the colour corresponding to the route in the alpha-numeric display.

Five databases are connected to the MIGA system. A road database holds information of the geographical area in question. A customer database holds information of each customer.A fleet database holds information about the vehicles in the fleet. An order database holds information of the customers to be served within the planning horizon. Finally an internal route and scheduling database holds information on the present planning situation. The road database is not at present implemented in the standard MIGA system but existing road databases may be connected to MIGA.

As earlier mentioned the main menu is always present on the screen. If offers the following sub-menus:

$$
\begin{aligned}
\text { - File : } & \text { Controls all input/output } \\
& \text { to file } \\
\text { - Print : } & \text { Controls printing of data } \\
& \text { from database } \\
\text { - Display : } & \text { Controls display of data } \\
& \text { from database } \\
\text { - solve : Controls use of solution } & \text { methods } \\
\text { - Improve : } & \text { Controls use of improve- } \\
& \text { ment methods } \\
\text { - Edit } & \text { Controls editing of the } \\
& \text { solution } \\
\text { - Problem : } & \text { Controls the problem de- } \\
& \text { finition } \\
\text { - Database : } & \text { Controls reading from } \\
& \text { the database and editing } \\
& \text { the database } \\
= & \text { Controls termination of } \\
& \text { of the program }
\end{aligned}
$$

The display menu makes it possible to control all the output to the listing window and the map window of the screen.

The solution menu allows choice between four heuristic solution methods for problems which are not time constrained and three heuristic solution methods for problems with time window constraints. The four methods are " hardest, savings, insertion, and two-phase. A more detailed description of the methods may be found in Sørensen [9]. Numerical experiments seem to show that two-phase usually gives the best results. The three methods for time constrained problems are hardest, saving, and insertion [9]. The methods bear the same names as the non-time constrained solution methods and as such they are generalizations of these methods. Here experiments shows that insertion usually gives the best results. All methods are especially adapted for use in an interactive environment. 
The improvement menu makes it possible to improve solutions from the solution menu or solutions obtained by an interactive dialog between the user and MIGA.

The edit menu gives the user access to a complete route and schedule editor. This implies that the user can edit the planning situation and see the consequences immediately. The user may e.g. move customers, connect customers, prohibit connection between customers, or release special customers or pairs of customers.

\section{The System Hardware}

The system hardware will run on IBM compatible personal computers. The computer schould be internaliy equipped with 640 . Kbytes of RAM memory with either two 320 kbytes disc drives or one 320 kbytes disc drive and one $10 / 20$ Mbyte hard disc. Furthermore a mechanical mouse is needed as pointing device. The screen shall be a colour graphics screen with a spatial resolution of 640 dots vertical and 200 dots horizontal. The standard colour resolution is 16 possible colours for each dot. The price of the software will be approximately us $\$ 7000-9000$ plus geocoding, maps and training.

\section{The System Performance}

Apart from the solution menu usual operations require les than a second i.e. MIGA works on-line. A 100 point problem without time constraints can be solved by twophase in 1-2 seconds on an IMB PC/AT. UsualIy the improvement operation improves the solution by some $5-8 \%$ and manual changes may improve the solution by $5 \%$.

A 100 point problem with time constraints can be solved by insertion in 7-15 seconds on an IBM PC/AT. In addition manual changes may also here improve the solution.

Problems with several hundred customers may easily be solved.

\section{References}

[1] M.A.G. Bocxe and C.B. Tilanus, "Testing vehicle scheduling programs for milk collection," European Journal of Operational
Research, Vol. 20, pp. $25-33,1985$.

[2] S. Belardo, P. Duchessi and J.P. Seagle; "Microcomputer graphics in support of vehicle fleet routiry," interfaces, Vol. 15, pp. 84-92, November-December 1985.

[3] I. Bodin and B. Golden, "Vehicle routing software for microcomputers: A survey,"

in Impacts of Microcomputers on Operations Research edited by S.I. Gass, H.J. Greenberg, K.I. Hoffman and R.W. Langly: New York: North-Holland, 1986, pp. 65-72.

[4] B.I. Golden and T. Goodwin, "Microcomputer-based vehicle routing and scheduling software, " computers and operations Re-

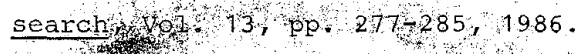

[5] B. Lotblden and E.A. Was.il, "dompeterized vehicle routing in the soft arink lifgo try," Operations Research, Vol, $35, \mathrm{pp}, \mathrm{g}$ 6-17, January-February 1987 .

[6] K.o. Jörnsten, O.B.G. Madsen and B. Sørensen. "Exact solution of the vehicle routing and scheduling problem with time windows by variable splitting," Research Report 5/1986 from IMSOR, The Institute of Mathematical statistics and Operations Research, The Technical university of Denmark, DK-2800 Iyngby, Denmark, march 1986.

[7] A.W.J. Kolen, A.H.G. Rinnooy Kan and H.W.J.M. Trienekens, "Vehicle routing with time windows," Operations Research, vol. 35, pp. 266-273, March-April 1987.

[8] M.M. Solomon, "Algortihms for vehicle routing and scheduling problems with time window constraints," Operations Research, Vol. 35, pp. 254-265, March-April 1987.

[9] B. Sørensen, Interactive Distribution Planning. PhD thesis from IMSOR, The - Institute of Mathematical statistics and Operations Research, The Technical University of Denmark, DK-2800 Lyngby, Denmark, January 1986. 